\title{
Kunstcoop: Experiencias de mediación artística en Alemania
}

\author{
Kunstcoop: experiences of art mediation in Germany
}

\author{
JAVIER RODRIGO-MONTERO \\ Proyecto pedagógico-cultural TRANSDUCTORES \\ javier_463@yahoo.es
}

Recibido: 16 de diciembre de 2013

Aprobado: 11 de septiembre de 2014

\section{Resumen}

Este artículo analiza el término mediación artística desde el ejemplo de las prácticas educativas del grupo de mediadoras alemanas Kunstcoop. Para comprender estas experiencias, se relata el proceso de construcción y marco institucional del grupo, su política educativa bajo la perspectiva de la pedagogía crítica, y su desarrollo intermedio como práctica interdiscursiva. Se ejemplifica el trabajo colaborativo del grupo desde sus proyectos como procesos deconstructivos en educación artística que describen un nuevo espacio de actuación de la educación en museos y centros de arte.

Palabras clave: mediación artística, educación artística, desconstrucción, pedagogía crítica, educación en museos, Kunstcoop.

Rodrigo-Montero, J. (2015): Kunstcoop: Experiencias de mediación artística en Alemania. Arte, Individuo y Sociedad, 27(3) 375-393

\begin{abstract}
This article analyses the term art mediation taking as example the educational practices of the German group Kunstcoop. In order to understand these experiences this text describes the process of construction and the institutional frame of the group, as well as its educational politics, under the perspective of critical pedagogy, and its in-between development as interdiscursive practice. The collaborative work of the group is exemplified from its projects as deconstructive processes in art education that informs a action framework in gallery and museum education. Keywords: Artmediation, art education, deconstruction, critical pedagogy, museum education, Kunstcoop.

Sumario: 1. Preámbulo: Mediación artística - educación artística. Definición y relación, 2. Kunstcoop. Origen de un proyecto de mediación en NGBK, 3. El trabajo interdiscursivo de mediación artística. Dentro y fuera de la institución, 4. Desplazamientos críticos: dos ejemplos de interdicursividad, 5. Pedagogía crítica: la mediación artista como proceso desconstructivo, 6. Prácticas desconstructivas críticas: el projecto Unterbrochenen Karrieren -Partneshaften. 7. Epílogo. Referencias.
\end{abstract}




\section{Preámbulo: Mediación artística - educación artística. Definición y relación ${ }^{1}$}

El termino mediación artística -"Kunstvermittlung"- es un concepto desarrollado de manera sistemática en la literatura sobre educación artística alemana. Desde una perspectiva amplia la palabra mediación artística ofrece un abanico inabarcable de posibilidades y estrategias educativas, comunicativas y de acercamiento a diferentes sectores que conforman tanto el público oficial como el no oficial del discurso del arte dentro de las más diversas instituciones. Por lo tanto es un término complejo de definir o abarcar en una sola definición. La mediación artística como tal se produce, aplica, reproduce y extiende dentro de campos muy diversos que están siempre en relación directa con el contenido y los parámetros del arte contemporáneo más reciente. $\mathrm{Su}$ campo de actuación puede ser en Bienales de arte, macro-exposiciones como la Documenta de Kassel o la bienal de Merco-Sul en Porto Alegre o la Bienal de Sâo Paulo. Puede también relacionarse con experiencias de larga trayectoria implicadas en barrios, comisariado independiente o en cambio en instituciones consagradas del arte como museos de arte moderno ${ }^{2}$. También cubre exposiciones de arte en sociedades o espacios de arte alternativo, en espacios formativos dentro de los museos, tanto de arte moderno contemporáneo, como además en diversos tipos de museos como son los museos etnológicos o los museos de barrio. ${ }^{3}$

Como podemos deducir a partir de lo descrito hasta este momento, la mediación artística es un concepto más general y extensible que la educación artística o la denominada educación estética, que tiene parte de sus principios arraigados en la década de los años 70 en Alemania (Otto, 1974). El problema de definir un marco para la mediación artística es aun más problemático que definir el mismo campo de actuación institucional del arte contemporáneo. Mucho más aún en la actualidad después de la extensión y desmaterialización del mismo concepto de arte (Lippard, 1997). Precisamente ahí radica su mejor baza, y a la vez probablemente su mayor desventaja. Y esta es la gran paradoja donde se mueve este campo. Desventaja en el sentido de la dificultad de concretar un campo de profesionalización y limitación de la figura de la mediadora de arte. Pero, como la otra cara de la misma moneda, su mayor ventaja es que se inserta y se desarrolla como un campo intermedio ("Zwischenraum") o zona híbrida tal como propone Maset (2000:31), entre diversas instituciones, políticas, saberes y discursos. Esta situación permite finalmente una mayor movilidad y un comportamiento más complejo de la mediación artística en diferentes niveles, es decir un trabajo, tal como señala Eva Sturm (2000), que podemos definir como interdiscursivo ${ }^{4}$.

Esta indeterminación conlleva que haya un gran desacuerdo en la definición del mismo término, y consecuentemente en las funciones y características que debe asumir una mediadora de arte. El término "Vermittlung" ("mediación") conlleva ya una gran discusión en su concepción general en alemán, tal como sindica Sturm (2002:27) a la hora de relatar la gran diversidad de campos culturales e instituciones sociales que "median"o hacen de "intermediarias". El añadir la partícula "arte" y desarrollar un nuevo término, "Kunstvermittlung", complica aun más su propia definición. Pese a ello se pueden perfilar tres campos de actuación que ayudan a percibir perspectivas diferentes en torno a este tipo de proyectos: 
Primero. En numerosas ocasiones la mediación artística ha sido estructurada siguiendo paradigmas educativos. Se concebía entonces como proceso de enseñanza/ aprendizaje dentro de la educación artística contemporánea. Esta visión ha sido recogida en diversas acepciones señalando de forma explícita el elemento "mediador" de la estética (Brock, 1977), o dentro de un paradigma educativo más amplio (Selle, 1990). Esta acepción es lo que definiríamos como educación en museos o lo que en el campo anglosajón comporta el término "Gallery education", educación en exposiciones o centros de arte, con una tradición basada en la nueva museología y la museología crítica.

Segundo. En otras ocasiones de forma más amplia - y en muchos caso dependiendo más de una tendencia o campo del mundo del arte-, se ha incidido de forma generalista en que la labor de comisariado, de programación de exposiciones, es una labor de mediación artística. Esta tesis es sostenible siempre y cuando dichos conceptos remitan a exposiciones organizadas que tienden a organizarse más horizontalmente y con estrategias interdisciplinares desde la museología crítica (Weil, R 1990) o nuevas formas de comisariado colaborativo o pedagógico. Estos proyectos detectan estrategias de participación y procesos de intercambio y visibilidad de diversos grupos donde la labor de investigación y la generación de dispositivos expositivos, de comunicación o de relaciones entre públicos o diversos grupos resulta un elemento importante en el trabajo de políticas culturales. En este caso las exposiciones se comprenden como proyectos culturales comunicativos propios del comisariado crítico (Bauman, 2002) y por allende la labor del comisariado es una de mediación. Aunque esta tendencia es muy controvertida, ya que como señalan algunas críticas es fácilmente manipulable dentro del discurso neoliberal que empapa el arte como una economía creativa (Raunig, 1999). Por otro lado otras visiones más recientes critican esta tendencia porque simplifica y expulsa la labor de las trabajadoras de educación como agentes críticos, realzando unas "estéticas pedagógicas" y políticas coloniales sobre otros saberes educativas o agencias políticas que tengan las comunidades educativas (Rodrigo, 2010). Pese a estas críticas, no obstante esta perspectiva intenta resaltar el elemento político, de gestión, así como la labor de negociación del comisariado que también es factible que refleje una práctica de mediación artística ${ }^{6}$, además de la importancia de tradiciones de crítica institucional y de crítica de la representación que conlleva el comisariado (Fontdevila, 2013).

Tercero. Finalmente habría que remitirse a una expansión de la definición de mediación artística, que recoge elementos de las dos tendencias anteriores, y propone una relación directa con el discurso del arte contemporáneo y las nuevas formas de crítica institucional. Esta postura se genera dentro y fuera del sistema del arte, como una turbulencia nueva que remite al estado dinámico del arte y a los límites de sus instituciones. En este caso definiremos la mediación artística siguiendo una línea argumentativa que, situándola en referencia al arte contemporáneo, explota, desdibuja y aplaza el discurso artístico en relación al campo cultural y social desde la década de los años 60. El arte contemporáneo como proceso cultural se desplaza, emplaza, y se mezcla con otras prácticas culturales (Rollig 2000), siendo el campo de la mediación artística un campo en expansión que el arte tiende cada vez más a experimentar y aplicar. Siguiendo esta línea se encuentra la aproximación de Pierangelo Maset 
(2002,2004 2007). Este autor definirá la mediación artística como campo intermedio, que provoca un aplazamiento y transformación del campo de acción - y por lo tanto de producción- del arte contemporáneo en terrenos no explorados comúnmente. Según su perspectiva, la dimensión expansiva del término "arte" hacia otros terrenos de investigación, parte del mismo germen del arte, como proceso de diferenciación continua, que adquiere para sí misma cada vez un mayor rango de estructuras mediadoras produciendo comunicaciones imposibles, impredecibles o latentes en potencia. Por ello la mediación artística produce inevitablemente procesos de comunicación/medicación paralelos de segundo orden dentro de un sistema cultural como es "el arte". Dichos procesos impulsan nuevas relaciones, aperturas y fricciones de los sistemas autopoiéticos con sus entornos, entendiendo que el campo cultural del mundo del arte es un sistema autopoiético ${ }^{7}$. En este punto la consideración de la mediación artística se nutre de elementos ajenos al mundo del arte que finalmente son incluidos en el pensamiento estético (Seel, 1985), generando espacios de hibridación y zonas de contacto constantes.

Con estas tres definiciones desde diversos ámbitos de las tradiciones alemanas nos encontramos con un campo complejo de interrelaciones y de competencias superpuestas en la figura de la artista, mediadora, educadora o comisario de arte ${ }^{8}$. Finalmente acudo, para acentuar la naturaleza "inestablemente" fructífera de este término, a la definición acuñada por una de las fundadoras del colectivo Kunstcoop: Carmen Mörsch. Esta autora sintetiza e intenta abarcar las posibilidades y las nuevas extensiones que el término mediación artística -"Kunstvermittlung"- puede tener:

"El término mediación artística es una palabra comodín en alemán que cubre elementos de diversas prácticas como la educación de museos y galerías de arte, community art o formas de arte participativas e interventivas.(...) Es traducido como mediacióneducación- comunicación artística para poder subrayar sus amplias implicaciones así como su significado especifico en el trabajo de Kunstcoop. " (Mörsch 2002, 183, nota 1).

\section{Kunstcoop. Origen de un proyecto de mediación en NGBK}

El origen de Kunstcoop hay que situarlo en la preocupación por un grupo de mujeres artistas/mediadoras. Todas ellas estaban vinculadas a la ciudad de Berlín, donde desarrollaban además de sus propias prácticas otro tipo de proyectos sociales, culturales y educativos donde poder establecer su campo de acción (NGBK, 2002). Sería precisamente a raíz de un seminario coordinado por Carmen Mörsch en 1999 en el Institute für Kunst in Kontext de Berlín titulado "Marktlücke"9("Huecos del mercado"), cuando estas mujeres se encuentran y deciden fundarse como grupo de mediación artística debido a sus intereses compartidos. Este grupo de artistas difícilmente encuentran que puedan ser comprendidos únicamente dentro del discurso del arte, ya que “...ningún/a comisario en Berlín (...) nos ha planteado de manera clara un presupuesto para que podamos ayudar al programa de su institución con un proyecto piloto de mediación artística sobre arte”. (Mörsch 2002, p.78).

Para su consolidación Kunstcoop deciden presentarse como un proyecto cultural a la convocatoria principal de la asociación NGBK (Neue Gesellschaft für Bildende Kunst). Precisamente el marco de trabajo de esta institución es el más apropiado para 
este grupo interdisciplinar de artistas. NGBK, fundada en 1969, se plantea como laúnica sociedad de arte contemporáneo que se organiza y se administra de forma totalmente democrática según el beneplácito de sus más de 350 miembros internacionales. NGBK es junto con otro centenar de asociaciones de arte contemporáneo diseminadas en Alemania una institución cultural que, a modo de asociación para las artes, promueve una programación abierta con diversos contextos que afectan a la producción del arte contemporáneo. Su dinámico sistema se plantea en grupos o células de trabajo que cambian cada año en función de los proyectos seleccionados que se vayan a realizar y bajo una estructura democrática de coordinación (Behrens y Jans, 2011). Al principio de cada temporada los miembros principales se reúnen y votan los proyectos que van a ser expuestos y realizados por $\mathrm{NGBK}^{10}$. Se incluye por tanto no sólo un espacio expositivo cerca del centro en Berlín, sino además proyectos paralelos, ciclos de conferencias, exposiciones en otros centros, talleres, visitas guiadas en torno a los más diversos contenidos artísticos contemporáneos ${ }^{11}$. La actual directora de NGBK, Leonie Baumann, señala cómo esta institución cultural responde a un marcado carácter experimental ya que se fundó para preservar un espacio a determinadas clases sociales donde poder participar en la vida cultural y en las artes (Baumann 2002:178).

Bajo esta perspectiva, en la primavera del año 2000, Kunstcoop se presentó a la convocatoria para establecer una programación continua de proyectos de mediación artística que acompañarían de forma paralela al programa oficial de NGBK. En esta reunión Kunstcoop logró establecerse como el primer proyecto cultural seleccionado a desarrollarse en el siguiente. Cada proyecto que realizasen debía presentarse y discutirse con cada grupo o célula de trabajo, previa aceptación del comité asesor general. Esto supuso una colaboración profesional única dentro del panorama europeo en cuanto a asociaciones de arte, ya que dicho programa no se establecía como complementario al programa principal, ni tampoco como un programa de community arts o de "outreach", es decir, de captación de nuevos públicos. Más bien se consideró como un proyecto cultural de mediación artística que correría paralelo a las exposiciones de NGBK, con un cierto grado de de independencia. Esta "semiautonomía" le daba un marco de libertad para ahondar y reflexionar en los temas y problemáticas que el mismo grupo requería.

\section{El trabajo interdiscursivo de mediación artística. Dentro y fuera de la institución}

He utilizado anteriormente el término de "semiautonomía" consciente de que en términos profesionales podría suponer una contradicción ante la situación de trabajo de Kunstcoop descrita hasta ahora. Claramente sus proyectos eran financiados conjuntamente con el mismo presupuesto que otro proyecto más de exposición. Realmente nunca tuvieron que entrar en discusión directa con la comitiva de NGBK, pero el problema del trabajo constante dentro de las diversas células de trabajo generó ya desde el cuarto proyecto una actitud distante, en determinados casos, a la hora de proponer de nuevo una participación activa de los miembros de Kunstcoop.

Esta controversia institucional queda perfectamente analizada por Carmen 
Mörsch ${ }^{12}$ al intentar desgranar la dificultad de realizar prácticas no legitimadas, que realmente suponen un ataque a los comisarios que plantean las exposiciones. Mörsch plantea la dificultad actual de crear espacios nuevos de dinamización cultural autónomos en las diversas instituciones que configuran el espacio social actualmente y las contradicciones que emergen de estas relaciones.

En la práctica real el trabajo de Kunstcoop fue puesto en cuestionamiento debido a algunos prejuicios de equipos comisariales que pretendían mantener la inmanencia del proyecto artístico propuesto por las personas del grupo de trabajo, sin que éste se viera afectado por las propuestas de mediación artística. Entre otras supuestas acusaciones, en la publicación de Kunstcoop se recogen, entre otras, la manida argumentación de que el trabajo de Kunstcoop suponía una simplificación y no estaba al mismo nivel teórico que el proyecto expositivo, cómo las artistas que componen Kunstcoop son de categoría " $\mathrm{b}$ ", o cómo dichos proyectos debería de ser más didácticos que artísticos (Mörsch 2002, p. 80).

Esta perspectiva obligó a Kunstcoop a posicionarse críticamente con estrategias alternativas. Antes que retirarse, optaron por realizar proyectos colaborativos precisamente con aquellas instituciones que quedaban excluidas del discurso del comisariado, al no comprenderlas como público potencial. Esta táctica supuso para el grupo desentenderse previamente de una estructura cerrada de mediación, en relación vertical con un visitante discapacitado y sin voz. Las componentes de Kunstcoop optaron por establecer puentes con una gran variedad de participantes en la acción de mediación, con lo cual se aseguraban que habría un contacto más directo con la gente $^{13}$. De este modo un proyecto de guía o educación en el sentido de mostrar o enseñar una serie de preceptos se tornaba en un verdadero proceso de diálogo cultural bajo las consideraciones de la didáctica dialógica (Freire, 2000).

Este espacio interinstitucional creado por Kunstcoop provocó una segunda estrategia alternativa en sus prácticas. Antes que esperar usar el potencial y las estructuras que la propia institución de NGBK ofrecía, el grupo creó su propia estructura de investigación, captación y diálogo con estas instituciones que nada tenían que ver en principio con NGBK. La situación de Kunstcoop era altamente arriesgada, invisible para la institución, en un doble sentido, como una "correa doble" (Mörsch 2002, p. 84). Desde dentro de la institución acarreaba una lucha constante con los grupos de trabajo para alcanzar un estado de legitimación; y fuera además conllevaba la dificultad de construir procesos de mediación independientes con otras instituciones no relacionadas con el arte.

\section{Desplazamientos críticos: dos ejemplos de interdicursividad}

El trabajo de Kunstcoop se sitúa en los pequeños huecos donde la institución no puede ejercer un control total, donde las relaciones de poder son imposibles de bloquear (Foucault, 1982). Sus prácticas se basan en micropolíticas que desarrollan "huecos" o "intersticios" de resistencia en forma de actividades educativas, y que finalmente movilizan los planteamientos a gran escala de la institución, flexibilizando sus comportamientos oficiales e introduciendo disonancias o perturbaciones temáticas partir de la relación con otros espacios ${ }^{14}$. Antes que resaltar estructuras o 
escenificaciones dentro del marco de la galería o la exposición, Kunstcoop sale al espacio público, colaborando de manera activa con la misma comunidad que habita el espacio expositivo. Es una estrategia crítica de "desplazamiento" en otros discursos paralelos al discurso mantenido por la misma exposición. Este nuevo emplazamiento crítico se puede observar en estos dos ejemplos donde el espacio de la acción mediadora queda ubicado más allá de los muros expositivos de NGBK.

El primer proyecto es un ejemplo de colaboración con la comunidad de vecinos que habita el patio interior donde se halla la sala de exposiciones ${ }^{15}$, promoviendo un proyecto social a raíz de una exposición sobre la relación de diversas comunidades autoorganizadas denominado "evolutionare Zellen"16 (Jorek 2002:162). La mediadora Beate Jorek realizó el proyecto desde Abril a Diciembre del año 2002 titulado "Gesellschaftsspiele und Nachbarshaftenbrücken" ( juegos sociales y puentes de la comunidad"). Éste consistió en una serie de instalaciones socio-lúdicas que intentan conectar los diversos aspectos culturales de la exposición con la vecindad, los jóvenes y la comunidad de invidentes colindante al espacio expositivo, pero excluida por un muro. El proyecto creaba una serie de conexiones interinstitucionales, concluyendo con una propuesta de intervención artística en el espacio adyacente de la galería: un puente móvil, que permita el acceso real al patio de NGBK desde el otro lado del muro. ${ }^{17}$

Con esta mediación, como mesa de discusión e interacción, se cuestiona el acceso físico del espacio expositivo fuera del mismo sistema del arte, en forma de un puente móvil simbólico que permite el acceso desde otro patio interior, el de Naunyn Ritze.

El segundo desplazamiento se materializa en la acción denominada "Familienstudio Kotti". Este proyecto desarrollado por Bill Masuch propuso la creación de un estudio fotográfico alternativo en uno de los centros neurálgicos del barrio turco: Kottbuser Tor. Esta es una plaza donde confluyen dos líneas de metro y paradas de autobuses. Una zona de cruces urbanos donde se da una variada mezcla de estratos sociales: desde parados, a sin techo, familias turcas, jóvenes turcos de tercera generación, estudiantes y familias alemanas asentadas... Bajo este escenario la medidora-artista decide realizar un estudio fotográfico temporal paralelo a una exposición sobre la concepción de las diversas familias en todo el mundo a través de la fotografía (Masuch 2002). La autora invita a la gente a fotografiarse como familias a diversas personas, creando imágenes abiertas del cruce de diversas familias culturales en la zona.

En este caso el desplazamiento es doble, en el sentido físico y también simbólico/ institucional:

Físicamente el espacio de trabajo deja de ser la galería, la caja blanca, para desplazarse críticamente a un centro de la ciudad que actúa como punto neurálgico de idas y venidas de una gran masa de gente. Un espacio de cruce del mismo barrio donde se sitúa NGBK.

Institucionalmente se consigue poder contar con la colaboración del Teatro Ratten. Un proyecto social de integración de la población sin techo de Berlín que se inserta dentro de la programación alternativa del Volskbühnen de Berlín. Esto supone el uso y la integración en el sistema del arte del potencial cultural de un proyecto comunitario existente enfocado a la integración y la adaptación de los sin techo.

Además simbólicamente este proyecto reconfigura el contexto de acción de fotografiar una familia. La acción de mediación se asienta sobre la creación de 
situaciones especiales, de entornos culturales integradores y perturbadores. Cada paseante puede inscribirse en la acción y posar con diversos actores del teatro, otras personas, adoptar diferentes papeles y poses para retratar la gran diversidad de familias urbanas que configuran el mapa social de esta zona de la ciudad. Se consigue desmantelar el código fotográfico que describe una familia no sólo en su aspecto formal o técnico, sino en su origen y espacio social de producción donde dicho aparato técnico se localiza. Así se analiza la producción de arte y del artista como productor cultural, que contempla un efectivo proceso participativo de reconfiguración del lugar específico ${ }^{18}$. Con ello se logra establecer un vínculo político y social con el espacio circundante. A la vez se diseña una situación de confrontación y articulación de las diferentes identidades que conforman las familias posibles que transitan este espacio, y se desplaza el discurso de la exposición a una zona de incertidumbre productiva.

Finalmente con el conjunto de todas las fotografías realizadas se logra, gracias a la ayuda de una tienda de fotos cercana, revelar y ampliar todas las diversas escenificaciones transculturales. Así las nuevas ampliaciones adornan los escaparates de las tiendas de la calle de Oranienstrasse, precisamente la calle donde se sitúa la galería de NGBK. La acción de mediación retoma un desplazamiento final en la misma esfera pública que configura y sitúan las prácticas sociales de los colectivos, que retoman el arte en la misma acción, extendiendo la estrategia fotográfica a una instalación colectiva de arte público.

\section{Pedagogía crítica: la mediación artista como proceso desconstructivo}

Las prácticas de Kunstcoop se podrían insertar dentro del paradigma de la pedagogía crítica, ya que plantean procesos de participación cultural desde la cultura y los medios propios de cada colectivo, buscando procesos de alfabetización cultural críticos. En este sentido es necesario reconsiderar las prácticas educativas en los espacios expositivos a la luz de las prácticas y enfoques teóricos propios de la pedagogía crítica en museos (Hooper-Greenhill 2000, Padró 2004). Desde la museológica critica se analiza cómo cada práctica expositiva entraña una determinada política cultural que margina y excluye determinadas culturas no "oficiales", proponiéndose por ello recomponer los museos como espacios de conflicto y negociación cultural. La propuesta de la pedagogía crítica enfoca el espacio formativo dentro de marcos institucionales determinados, esclareciendo y reaccionando contra las ideologías y paradigmas que se esconden tras las prácticas educativas (Beyer, E. y Linston, P. 2001). Comprende las escuelas como espacios de conflictos y fricciones entre diversas culturas, entre las que se incluyen la cultura del profesorado, la cultura de los estudiantes, la cultura administrativa, o también las culturas familiares. Las aulas pasan a ser consideradas espacios de producción cultural. Son aparatos ideológicos que regulan la distribución social de los estudiantes, alabando y menospreciando cualidades ${ }^{19}$ propias de una cultura dominante.

La pedagogía critica ha resaltado constantemente el carácter pragmático que tienen las ciencias sociales, y la necesidad de establecer un vínculo continuo con el contexto sociocultural desde donde se asientan las escuelas y espacios formativos. Por ello la práctica educativa en arte debe de ser ante todo un proceso práctico de aplicación/ 
transformación de la realidad estética circundante y del mundo experiencial del arte ${ }^{20}$. Tomando como eje de su argumentación la consideración de que el "arte no existe al menos que no sea aplicado" (Pazzini, 2000), se debe reconsiderar la educación/ mediación artística como una de las formas de aplicar arte. Desde esta perspectiva Eva Sturm (2002) introduce el concepto de "educación artística como desconstrucción". La desconstrucción es comprendida como una práctica re-constructiva que defiende y expone la contingencia de los diversos discursos desde la falta de un centro rector dentro de un texto u obra de arte. Las prácticas de mediación artística se nos presentan como un proceso continúo de desconstrucción que fomenta la inevitable diferenciación crítica que la educación estética articula. Su fin se presentará entonces como "un concepto de aplicación que disemina, que continua, que genera algo impredecible" (Derrida 2000, p. 29 en Sturm 2002, 28).

La mediación artística se sitúa entonces como un proceso impredecible de articulación continua de constelaciones significativas desde una estrategia crítica que "debería proliferar continuamente, desarrollarse como un rizoma y tomar varias formas..." desde la bifurcación y expansión en todas direcciones de la superficie hacia la densificación en nódulos y nudos" (Sturm 2002, p.35). Desde este punto de vista no se percibe el final de un proceso, no tiene un único objetivo final o un punto de cierre. Es un aprendizaje impredecible, en zonas inapropiadas. Este tipo de mediación supone el principio de una nueva orientación en educación artística crítica que potencie las estrategias propias de la producción de arte donde el arte siempre existe como elemento innato, potencia procesos de diferenciación a través de micropolíticas. Estos espacios que emergen se demarcan como espacios de producción cultural dentro de una la pedagogía fronteriza (Giroux, 1997). Éste es precisamente el marco donde es posible diseñar proyectos educativos críticos que transciendan los límites de los diversos discursos e instituciones ofreciendo "las circunstancias para que los estudiantes se dediquen a levantar nuevos mapas culturales como forma de resistencia" (Giroux, 1997, p.51), y no simplemente repitan o reinscriban los mapas recibidos.

\section{Prácticas desconstructivas críticas: el projecto Unterbrochenen Karrieren - Partneshaften}

Se puede afirmar que la práctica educativa de Kunstcoop se situó bajo este enfoque crítico-deconstructivo. Sus políticas de educación e intervención se orientaron al establecimiento interdiscursivo de diversas culturas que cruzan y reconfiguran ya no sólo el espacio físico de la galería, sino en el espacio discursivo del arte - su dimensión social y política- y las disemina en un topos común que continuamente se dilata y expande. La desconstrucción crítica que Kunstcoop realiza conlleva un proceso de "destorritalización" del terreno artístico (Maset, 2002) para incrementar y defender un espacio intermedio ${ }^{21}$ donde se sitúa y se desarrolla la mediación artística. En consecuencia pone en contradicción sus límites y modos de acceso, trabajando desde y a través de sus controversias (Mörsch, 2011).

Como ejemplo de esta práctica desconstructiva además de las dos estrategias de desplazamientos relatados anteriormente, podemos describir el proyecto de Nana 
Lüth y Carmen Mörsch desde diciembre del año 2001 a Septiembre del 2002. La exposición sobre la que se basan la acción mediadora se titulaba "Unterbrochenen Karrieren-Partnerschaften (Relaciones - carreras interrumpidas) mostraba el tema de parejas de artistas en los que uno de ellos había muerto debido a desarrollar la enfermedad del SIDA (Lüth, 2002). Después de la primera tentativa propuesta al grupo de trabajo encargado de coordinar esta serie de tres exposiciones, el proyecto de mediación centra su atención en un sector social que más que permanecer a la sombra del mismo debate artístico y que no obstante tiene mucho que decir: los diversos colectivos activistas de lesbianas y homosexuales que luchan por los derechos, la intervención estatal de enfermos de SIDA y las ayudas a los HIV positivos. Es decir expertos locales que pueden contradecir, investigar y dialogar como iguales sobre estos temas.

El proyecto de mediación artística consistirá no en un taller práctico sobre fotografía, o en una manipulación de diversos elementos, sino en un diálogo cultural con diversos grupos de activistas, en un proyecto de un año de duración. La primera parte de la acción se articulaba en una visita-discusión a las exposiciones de tres horas de duración donde se planteaban las diversas temáticas relacionadas con el SIDA y la homosexualidad. Se trabajaron las concepciones que se mostraban de la enfermedad, el estado actual de los enfermos, la falta de recursos para sobrevivir o las medidas de recorte de ayudas sociales para los medicamentos en Alemania. Más que una introducción al mundo del arte, las dos mediadoras/artistas se vieron envueltas en un proceso de discusión y confrontación de sus mismas perspectivas. Un proceso dialógico, que no sólo ayudó a los participantes a comprender e interpretar la realidad que el mundo de arte les ofrecía sino que "reconocimos las fronteras de nuestros propios marcos experienciales" (Lüth 2002, p.71).

Después de lograr este intercambio y proximidad con los diversos participantes, surgió por parte de los grupos implicados la necesidad de poder utilizar y desarrollar toda esta información que había sido elaborada durante las visitas-discusiones. Pidieron que se les concediera la oportunidad de desarrollar su propia voz dentro del sistema. De este modo la acción educativa devino en un taller que daría luz a un periódico. En este formato se recogerían una multiplicidad de elementos y discursos: las impresiones y discusiones que se dieron en forma de talleres de escritura creativa, una descripción del mismo taller con las intenciones de las mediadoras, un texto introductorio a la exposición, un conjunto de textos sobre la realidad del Sida y los grupos activistas redactado por los mismos participantes, una serie de poemas, artículos sobre la relación del arte y el SIDA a través de las condiciones de pobreza de los mismos artistas, y, finalmente, un artículo sobre la exclusión constante en proyectos educativos y en discursos museísticos de los colectivos homosexuales. El periódico fue diseñado y editado por los diversos colectivos durante el taller. Aparte, se incluyó un proyecto fotográfico en el mismo Berlín, que se recogería parcialmente en la portada, donde utilizaba las estrategias de la fotografía contemporánea para llamar la atención sobre la problemática del SIDA. 


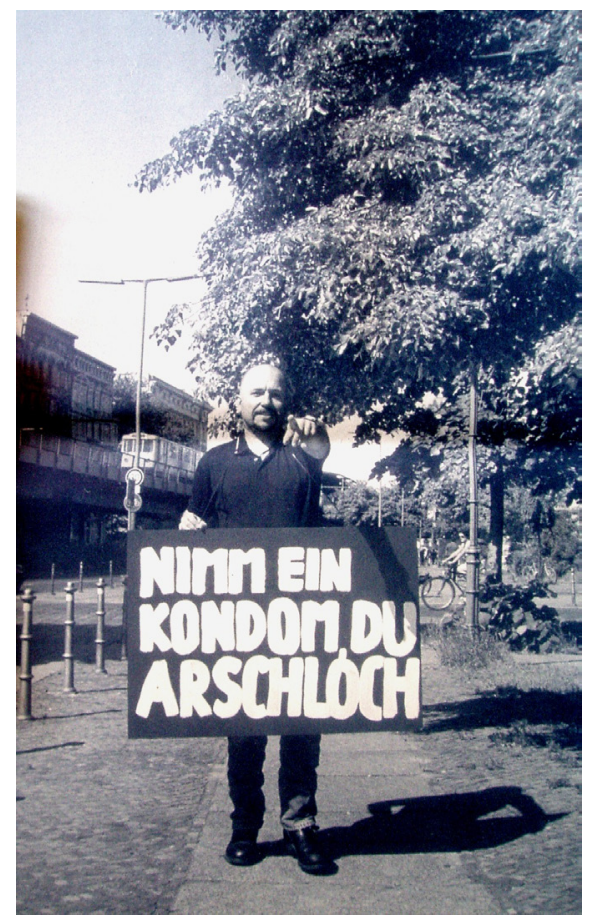

Figura 1. Portada del periódico generado desde el proyecto de Kunstcoop. La imagen representa una de las acciones políticas y performances generadas en el barrio de Kreuzberg con un cartel que indica: Ponte un condón, gilipollas! Imagen: Javier Rodrigo.

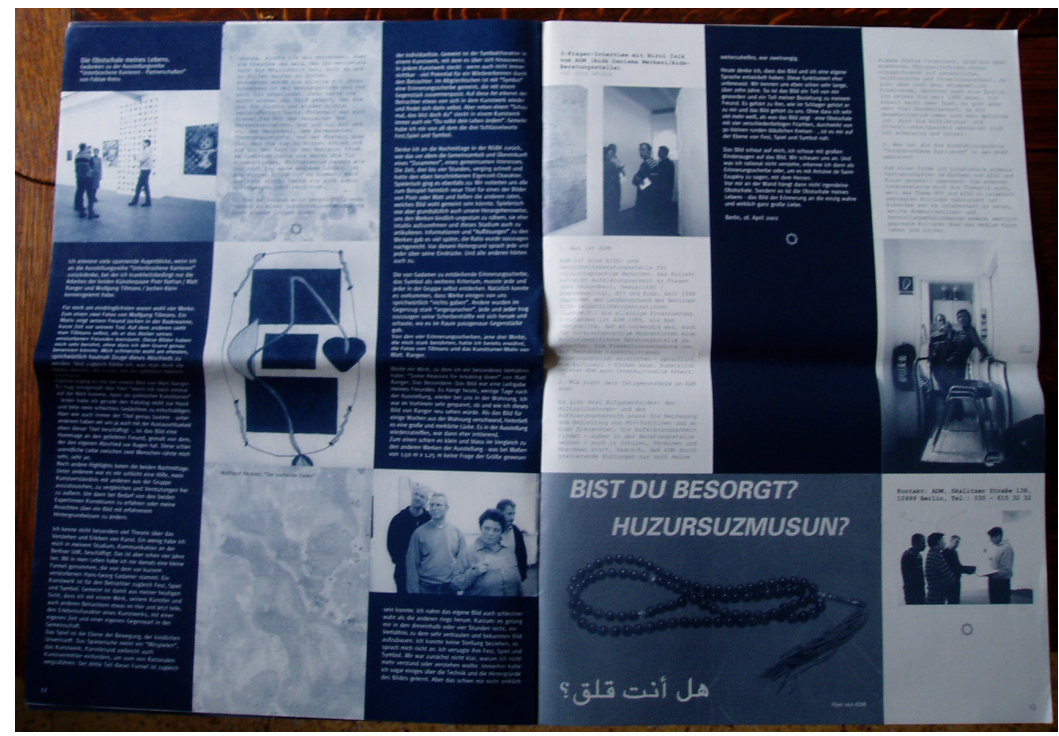

Figura 2. Imagen de la estructura interna del periódico, articulado a través de la interposición de columnas, colores, imágenes, gráficos y textos, que reflejan el entrelazado de discursos y saberes. Imagen: Javier Rodrigo. 
Este proyecto se enmarcaba como un proyecto cultural paralelo a la exposición, que usando el tema de las relaciones personales y SIDA como eje temático lograba profundizar y realizar una labor de mayor productividad y desarrollo cultural en su grupo receptor-productor. La práctica crítica así incidía en un proceso de creación y expresión de "legitimidad real" a partir de las identidades políticas y culturales concretas tal como señala Nana Lüth (2002). Desde la posición se retoma el uso del término de "realidad" o "legitimidad" (realness) en relación directa al cambio de roles y la performatividad subversiva de determinados sistemas, para resaltar la conexión directa con el marco experiencial del público o estudiantes en su entorno, en su contexto y en su campo cultural. Ahí estos visitantes ya no son públicos profanos, sino lectores iniciados y autónomos, sujetos con voz propia. En consecuencia es posible diseñar situaciones de confrontación desconstructivas, con el mismo discurso que sostiene la exposición de arte; y, desde ahí, poder desarrollar procesos diferenciales de participación desde una contranarrativa o reacción del propio agente o comunidad, que deja de ser receptor para ser co-autor, o mejor dicho "co-desconstructor". Este proceso educativo logra así desconstruir las estructuras ideológicas que enmarcan determinados discursos y desarrolla críticamente la potenciación intersubjetiva e interdiscursiva de cada sujeto desde espacios de resistencia (Sturm, 2003).

El periódico opera como una estrategia rizomática, en cuanto recoge y muestra una serie de prácticas deconstructivas sobre un discurso oficial una exposición, que se insertan críticamente en los "nudos" o cruces temáticos que el arte contemporáneo despliega en contacto e hibridación con otros campos. Podemos interpretar esta política desconstrucitva, en una estrategia pedagógica similar a la metodología crítica de la educación dialógica a partir de un tema generador o núcleo temático desde donde establecer procesos de alfabetización crítica tal como lo desarrolló Paulho Freire en su programa político de educación para la liberación (1990). Por otro lado, esta política de mediación crítica desconstruye el mismo concepto y visión que la exposición ofrece. Lo implosiona, despliega y contamina de otras relaciones, de otros subtextos, y de otros saberes inapropiados. Bajo esta perspectiva se consigue crear una serie de nuevas aplicaciones artístico-pedagógicas, de nuevas interpretaciones críticas en el marco simbólico y cultural desde las mismas obras de arte, "desde el arte hacia fuera", de forma "constelativa", asociativa y diferenciadora (Sturm, 2004).

\section{Epílogo}

El trabajo realizado por Kunstcoop es un ejemplo de cómo poner en práctica críticamente estrategias de mediación artística en relación a exposiciones o centros de arte, con sus tensiones y paradojas a contrapelo. No niega la tensión de saberes y políticas que cruzan la institución cultural, y tampoco niega o esconde estas contradicciones, sino que juega y media productivamente con ellas, a través de ellas. Esta política de mediación no desdeña, sino que por el contrario potencia, la participación directa de los diversos colectivos y grupos sobre los que articular el potencial cultural de cada asociación o grupo de colaboradores con los que se trabaja a través de la mediación artística. Sorprendentemente Kunstcoop logró mantener un 
proceso frenético, fructífero e indefinible de educación artística crítica, pragmática, desconstructiva dentro del contexto de una institución cultural, tensionando y mediando dentro y fuera de dicha institución. NGBK fue forzada, sutilmente a través de la deconstrucción del sistema del arte, a abrirse y expandirse en su espectro cultural, al mismo tiempo que se abrían sus contradicciones y paradojas, su marco institución cultural democrático a nuevos puntos ciegos e intersticios. Y esta apertura institucional es algo que no todas las instituciones, y los sujetos que las habitan y construyen, están abiertas a realizar. Este intenso proceso concluyó con una línea de trabajo desarrollada durante 18 meses, desde diciembre del año 2002 a febrero del año 2003, donde se dieron la suma de 38 proyectos de mediación artística.

La perspectiva crítica aportada por Kunstcoop configuró sentido a su práctica educativa, no como una educación artística complementaria, afirmativa o compensatoria de las propias exposiciones (Mörsch, 2002, p.91, 2011). Más bien, su práctica supuso un proceso cultural deconstructivo, paralelo, que abría zonas de incertidumbre y paradojas institucionales. Un proceso cultural y educativo que se insertaba en el magma de contenidos y relaciones que las exposiciones de arte contemporáneo ofrecen e "implosionaba" desde dentro sus límites, fricciones y contradicciones. Antes que situarse en una posición de poder oficial, y mucho antes que mantenerse detrás de la cortina de la educación artística como simplificación de contenidos o talleres manuales, Kunstcoop apostaron por la realización de proyectos realmente relacionados con la comunidad dentro de una aproximación híbrida de mediación artística crítica entre diversos campos: entre la educación feminista crítica (Luke y Gore, 1992), la investigación queer y posestructuralista (Lather, 2007) y las prácticas herederas del New Genre Public Art y las prácticas colaborativas. Esta última es una posición que sostiene una relación de la estética como un proceso social y ético relacional, tal como Kester defiende desde su paradigma de "estéticas dialógicas" donde el proceso artístico se construye desde el intercambio intersubjetivo e interdiscursivo (2004).

El trabajo de Kunstcoop fue un proceso enmarcado en la mediación artística crítica que nos recuerda cómo es posible rescatar los espacios o pequeños huecos invisibles de las estructuras sociales que configuran nuestra vida cotidiana como espacios de resistencia y solidaridad. La red institucional de contactos, los procesos educativos críticos de mediación artística que realizaron se continúan con el sello de una "profesión incierta", como antaño se definió a la educación en museos de forma peyorativa ${ }^{22}$. Sin embargo no pierde de vista los pequeños huecos y los desplazamientos discursivos donde incluir las posiciones de resistencia donde se localiza la mediación artística crítica como un acto de resistencia y espacio intermedio de paradojas productivas. Precisamente una perspectiva de mediación artística crítica encuentra su mayor potencial en las tensiones y pulsiones políticas desde donde se movió este grupo de mujeres: en las paradojas de la producción cultural crítica, en las paradojas de la democracia cultural y ciudadana desde el feminismo y la mediación, o en la gran contradicción de la enunciación oficial de los museos y otras instituciones culturales como espacios educativos y sus discursos oficiales como lugares de educación en contraste con la escasa renumeración y reconocimiento social del trabajo educativoreproductivo. En ese estar entre medias de las culturas y los saberes invisibles, las 
políticas de los grupos colaboradores y las de la institución, las pedagogías y los feminismos. Paradojas todas de las que seguimos aprendiendo y que son hoy en día cruciales, no solo ya en los museos o espacios expositivos, sino sobretodo en nuestras vidas.

\section{Referencias}

Agirre I. (2000). Teorías y prácticas en educación artística. Idea para una revisión pragmatista de la experiencia estética. Navarra: Universidad pública de Navarra. Arbeitsgemeinschaft deutscher Kunstvereine (ADK) und Neue Gesellschaft für Bildende Kunst (NGBK). (2002). Kunstvermittlung. Zwischen partizipatorischen Kunstprojekten und interaktiven Kunstaktionen. Berlin: Vice Versa.

Baumann, L. (2002). Ausstellungen sind Kommunikationsräume. En Neue Gesellschaft für Bildende Kunst (NGBK) (Ed.), Kunstcoop. Künstlerinnen machen Kunstvermittlung (pp.7-12). Berlin: ViceVersa.

Behrens W. y Jans, M- (2011). Una misión posible. Revista Humboldt 156 "Mediación artística”. Madrid/ Berlín: Goethe-Institut e. V., Humboldt Redaktion. Traducción del alemán: Ricardo Bada. http://www.goethe.de/wis/bib/prj/hmb/the/156/ es8622803.htm [Última visita 20/06/2012].

Beyer, E. y Linston, P. (2001). El curriculum en conflicto. Perspectivas sociales. Propuestas educativas y reforma escolar progresiva. Madrid: Akal.

Bourdieu, P. (1998). La distinción. Criterio y bases sociales del gusto. Editorial Taurus: Madrid.

Brock, B. (1977). Ästhetik als Vermittlung. Arbeitsbiographie eines Generalisten. Köln: Doumont.

Eisner, W. y Dobbs, S. (1986). The uncertain profession: Observations on the State of Museum Education in Twenty American Art Museum. Santa Monica. Ca: The John Paul Getty Museum.

Felshin, N. (Ed). (1996). But it is art? The spirit of art as activism. Seattle: Bay Press.

Fontdevila, O. (2013). Capgirar el museu. Interseccions entre el comissariat i l'educació en la perspectiva de la crítica institucional. Mnemòsine. Revista catalana de museologia. Barcelona: Associació de Museòlegs de Catalunya.

Foucault M. (1992). Microfisica del poder. Madrid: La Piqueta .

Freire, P. (1990). La naturaleza política de la educación. Cultura, poder y liberación. Barcelona: Paidós.

Freire, P. (2000). Pedagogía del oprimido. Madrid: Siglo XXI.

Giroux, H. A. (1997). Cruzando límites. Trabajadores culturales y políticas educativas. Barcelona: Paidós.

Gore, J. y Luke, C. (eds). Feminisms and Critical Pedagogy. New York: Routledge. Goodson, I. (1995). Historia del currículum. La construcción de las disciplinas escolares. Barcelona: Ediciones Pomares-Corredor.

Hoper-Greenhill, E. (2000). Museums and the Interpretation of Visual Culture. Londres y Nueva York: Routledge.

Jorek, B. (2002). Spiele. En Neue Gesellschaft für Bildende Kunst (NGBK) (Ed.), Kunstcoop. Künstlerinnen machen Kunstvermittlung (pp. 154-164). Berlin: 


\section{ViceVersa.}

Kester, G. (2004). Conversation Pieces: Community and Communication in Modern Art. Berkeley: University of California Press.

Known, M. (2002). Sittings of Public Art: Integration versus intervention. En Ault, J. (Ed.), Alternative Art New York 1965-1985 (pp. 281-319). Minneapolis: University of Minnesota Press and The Drawing Center New York.

Lather, P. (2007). Getting Lost: Feminist Efforts toward a Double(d) Science. Albany: State University of New York Press.

Lippard, L. R. (1997). Six Years: The Dematerialization of the Art Object from 1966 to 1972. Berkeley: University of California Press.

Lüth, N. (2002). Queens of Kunstvermittlung. En Neue Gesellschaft für Bildende Kunst (NGBK) (Ed.), Kunstcoop. Künstlerinnen machen Kunstvermittlung (pp.61-76). Berlin: ViceVersa.

Luhmann, N. (2000). Art as a social system. Stanford: Stanford University Press.

Maset, P. (2001). Praxis Kunst Pädagogik. Ästhetische Operationen in der Kunstvermittlung. Lüneburg: HYDE.

Maset, P. (2002). Aussichten an der Peripherie: Über Kusntvermittlung im Allgemein und Kunstcoop im Besonderen. En Neue Gesellschaft für Bildende Kunst (NGBK) (Ed.), Kunstcoop. Künstlerinnen machen Kunstvermittlung (pp.142-152). Berlin: ViceVersa.

Maset, P. (2005). Pedagogía del arte como forma práctica del arte. El concepto de

“operaciones estéticas". En: Beltrán Mir, L. (Ed.), Educación como mediación en centros de arte contemporáneo (pp: 56-66). Salamanca: Universidad de Salamanca.

Maset, P. (2007). Between Education and Participation: Aesthetic Operations. Engage. Estrategic Interpretation, 20, 29-33.

Masuch, B. (2002). Familienstudio Kotti - oder die Möglichkeit, sich gemeinsam neu zu erfinden. En Neue Gesellschaft für Bildende Kunst (NGBK) (Ed.), Kunstcoop. Künstlerinnen machen Kunstvermittlung (pp.131-142). Berlin: ViceVersa.

Mörsch, C. (2002). Enttäuschte Erwartungen, bestätigte Befürchtungen: Kusntcoop in der „Ordnung der Diskurse”. En Neue Gesellschaft für Bildende Kunst (NGBK) (Ed.), Kunstcoop. Künstlerinnen machen Kunstvermittlung (pp.79-91). Berlin: ViceVersa.

Mörsch, C. and the Research Team of the Documenta 12 education(2010) Documenta 12. Education. Vol2. Between Critical Practice and Visitor Services. Results of a Research Project. Zurich, Berlin: Institute for Art Education /Diaphanes.

Mörsch, C. (2011). Trabajo en contradicción. Revista Humboldt 156 "Mediación artistica". Madrid/Berlin: Goethe-Institut e. V., Humboldt Redaktion Traducción del alemán: Ricardo Bada. http://www.goethe.de/wis/bib/prj/hmb/the/156/ es8622803.htm [Última visita 20/06/2012]

Neue Gesellschaf für Bildende Kunst (NGKB)(Ed.) (2002). Kunstcoop. Künstlerinnen machen Kunstvermittlung. Berlin: ViceVersa.

Otto, G. (1974). Didaktik der Ästhetischen Erziehung. Hamburg: Braunsweig.

Padró, Carla (2004). La museología crítica como una forma de reflexionar sobre los museos como zonas de conflicto e intercambio. En Llorente, J. P. y Almazán, D. 
(Eds.) Museología crítica y arte contemporáneo (pp. 51-70). Zaragoza: Prensas Universitarias.

Raunig, G. (1999). Charon. Eine Ästhetik der Grenzüberschreitung. Wien: Passagen. Rodrigo, J. (2010). Educational tendencies: Discursos y líneas de tensión entre las políticas culturales y las educativas. En YProductions, p. 17. En línea: http://es.scribd.com/doc/33144918/Educational-Javier-Rodrigo [Consulta del 16/10/2013]",

Seel, M. (1985). Die Kunst der Entzweiung. Zum Begriff der ästhetischen Rationalität. Frankfurt am Main: Suhrkamp.

Selle, G. (1990). Experiment Ästhetiche Bildung. Aktuelle beispiele für Handeln and Verstehen. Hamburg: Rowohlt Taschenbuch Verlag GmbH.

Sturm, E. (2000). Give a Voice. Partizipatorische künstlerisch-edukative Projekte aus Nordamerika. En Muttenhaler, R., Posch, H. y Sturm, E. (Eds.) Seiteneingänge Museumsideee und Austellungsweisen (pp. 171-194). Wien: Museum zum Quadrat series.Turia Kant Verlag.

Sturm, E. (2002). Kunstvermittlung als Dekonstruktion. Neue Gesellschaft für Bildende Kunst (NGBK) (Ed.), Kunstcoop. Künstlerinnen machen Kunstvermittlung (pp.27-36). Berlin: ViceVersa.

Sturm, E. (2003). Kunstvermittlung und Widerstand. Schöppinger Forum der Kunstvermittlung. Transfer. Beiträge zur Kunstvermittlung, 2, 92-110.

Torres, J. (1991). El curriculum oculto. Madrid: Morata.

VVAA (2009). 40 Jahre NGBK: 1969 - 2009. Berlín: NGBK.

Weil, E. (1990). Rethinking museums. Washington/London: Smithsonian Institution Press.

\section{Notas}

1. Este texto fue estrito entre 2004 y 2005 , y actualizado durante el segundo trimestre del año 2013. El motivo de reemprender este texto es doble: Por un lado es la recuperación del texto este mismo año en un disco duro antiguo. Por otro lado existe un motivo de telón de fondo: han pasado casi ya más de 10 años de este tipo de prácticas, y aún hoy las problemáticas, líneas de trabajo se mantienen como temas actuales en lo referente a educación y mediación del arte, sobre todo en el panorama estatal, y más bajo la crisis y debilitación a mínimos de los departamentos educativos en museos.

2. En la Documenta 11 de Kassel (2002) se desarrolló un trabajo de mediación artística dentro de parámetros de comisariado independiente. En la Documenta 12 del año 2007 se generó un trabajo prolongado de mediación crítica, experimental que se materializó en una investigación-acción en equipo. Esta edición marcó un antes y después sobre las políticas de mediación crítica gracias a sus dos publicaciones. Así todo este trabajo está contemplado en una publicación, por el momento única, que relata el proceso de trabajo, los conflictos y las posiblidades políticas de otra mediación en exposiciones y museos Vease al respecto: Carmen Mörsch and the Research Team of the documenta 12 education (2009). Otros ejemplos, entre muchos se pueden citar aquí: en el año 2004 la Bienal de Berlín incluyó actividades con ciclos de conferencias, performances y programas de radio que se sostenían desde una perspectiva claramente educativo-comunicativa. Ahora 
este formato está más consolidado en otros macroeventos como Manifesta, la Bienal de Sáo Paulo, o Merco-Sur o la bienal intinerante Manifesta, donde incluso algunos ya cuentan con coordinadores estables de educación/ mediación durante todo el año, más allá de la organización del evento.

3. En especial muchos artistas debido a su trabajo en comunidad han optado por asentarse y desarrollar sus prácticas en museos de carácter comunitario y en contacto directo con los públicos, como por ejemplo en los ecomuseos en Francia (Ecomuseé), los Museos Hogar en Alemania (Heimatmuseum), o los museos de la comunidad en EEUU (Community Museum). En UK esta práctica es muy fructífera dentro de la denominada gallery education y en relación a tradiciones activistas y feministas heredadas de los años $60 \mathrm{y}$ 70. Véase www.engage.org

4. El termino interdiscursivo se utiliza en este sentido para designar la labor cruzada e intermedia de la mediación artística en las instituciones. En concreto se aplica desde la perspectiva de Eva Sturm sobre los trabajo artístico-participativos con dimensiones claramente educativas (2000, p. 189). En este sentido la mediación artística se sitúa en un cruce o nudo complejo donde se solapan y se entrecruzan diversas perspectivas que no sólo afectan a una institución internamente y a sus miembros, sino también a otras instituciones, a otros sectores no incluidos, y por lo tanto a otro tipo de discursos. Por ello el trabajo de la educación artística solapa y cruza estos discursos al mismo tiempo de forma rizomática.

5. Como por ejemplo enfermeras, hombres de negocios, teorías psicológicas, profesionales de educación social, de resolución de conflictos, o incluso personas religiosas...

6. Esta labor administrativa o de cultural managment queda ejemplificada por ejemplo en el Instituto de postgrado "Kunst in Kontex" de la Universidad de las Artes de Berlín (UdK) o en la School of Arts Institute of Chicago donde se dan cursos de administración y políticas culturales; y los estudiantes proponen sus practicas enmarcadas en políticas y administración cultural. http://www.kunstimkontext.udk-berlin.de/

7. Nicolas Luhman (2000) establece que todos los sistemas atienden a dos tipos de percepciones o consideraciones definitorias: un primer rango o percepción que corresponde a una visón desde dentro, que busca la constante estabilidad de sus elementos o componentes; y un segundo orden o percepción externa, que busca los trasvases o interrelaciones de los sistemas con otros sistemas y por ello sus compensaciones para su propia supervivencia posterior. Estas dos concepciones ayudan a poder esclarecer cómo un sistema como el arte necesita de unir parámetros internos por los que el arte es todo lo que un historiador o un artista dice qué es arte, y por otro lado como el arte evoluciona y se transforma en su propia definición que se interrelaciona con otras disciplinas como la ciencia, la antropología, los estudios culturales, la etnografía, etc....

8. Existen igualmente otras tradiciones de mediación artística en Latinoamérica que no contemplamos aquí: http://redmediacionartistica.cl/. En el panorama estatal existe también otra iniciativa parecida: http://mediacionartistica.org/. Somos conscientes de las diferencias con el enfoque que aquí planteamos, ya que muchas de estas redes se basan en conceptos más anglosajones o herederos de la educación popular bajo el prisma de "Desarrollo Cultural Comunitario" o "Artes comunitarias".

9. Dicho seminario versaba sobre la labor indefinida de la educación artística, la indeterminación de la práctica mediadora educativa y la dificultad de encontrar un 
espacio para su legitimización.

10. Cabe destacar como este proceso democrático de selección de NGBK permite una renovación constante de los proyectos en los grupos de trabajo o células denominados Arbeitsgemeinschaften (Comunidades o compañías de trabajo). Gracias a la concesión de una beca de prácticas profesionales dentro del programa europeo Leonardo de un trimestre a finales del año 2001 puede conocer y acceder a estructura propia de trabajo y coordinaron de esta sociedad: Cada grupo de trabajo debe contar siempre con la coordinación de al menos de un miembro fijo de NGBK de modo que pueda regularizar y ayudar en la realización y coordinación del proyecto. Cada grupo de trabajo coordina independientemente toda la labor de programación, comunicación, marketing e instalación, aunque siempre es ayudado y regularizado por los departamentos y el personal fijo que trabaja dentro de NGBK.

11. Dentro de la programación ofrecida por NGBK se han tratado los más diversos temas que van desde exposiciones entorno a la alienación y la colectividad en el trabajo, el sida, el arte latinoamericano ,o incluso español, así como estrategias de video activistas, redes auto organizadas, proyectos de arte público, etc... Véase al respecto la publicación que recoge el 40 aniversario del proyecto (VVAA,2009).

12. En el artículo titulado „Enttäushte Erwartungen, bestätigte Befürchtungen: Kunstcoop in der „Ordnung der Diskurse“(Expectativas decepcionantes: temores confirmados? Kunstcoop en el "orden del discurso") (Mörsch 2002,76-91) se expone el proceso de realización y la controversia entre las células de trabajo y el grupo y cómo fue afrontado en el proceso de negociación.

13. A modo de prueba de la red interinstitucional el libro que recoge las actividades de Kunstcoop (2002:170) muestra una relación de todos los cooperantes en los proyectos que incluye desde grupos de inmigrantes, comunidades de escolares, grupos de mujeres, asociaciones de activistas, talleres formativos para invidentes, teatros, institutos técnicos de higiene y medio ambiente, grupos de jubilados, etc....

14. Maset ha definido de forma específica como la mediación artística introduce perturbaciones y términos artísticos "nerviosos y disonantes" en el discurso del arte (Maset 2002). Esta reflexión se ha traducido en castellano en (Maset 2004) aunque en la traducción española se mantuvo el término comunicación de arte como traducción de "Kusntvermitlung", perdiéndose parte de la complejidad del alemán. Más aun cuando en un texto en inglés del autor, se traduce como art mediation, también traducible del alemán a veces como art- education o también como gallery education - educación en museos- en otras publicaciones, véase Mörsch et ander (2010).

15. NGBK e encuentra en Kreuzberg, el barrio turco de Berlín. La galería esta situada en la calle Oranienstrasse $n^{0} 25$, en el segundo patio interno. Sus inmediaciones tienen una herencia cultural activista fruto de la agitación social del 68 y su continuación con la contracultura del Berlín de la década de los ochenta. Este contexto es importante para entender el marco social y cultural donde se sitúan las exposiciones de NGBK rehuyendo de espacios más oficiales. Vease al respecto VVAA (2009).

16. Se traduce como "células evolutivas". "Evolutionäre Zellen". Éste es el título de una serie de exposiciones realizadas en el año 2002.El tema sobre que versaban eran proceso autoorganizativos independientes en la sociedad actual dentro de comunidades y sociedades alternativas. Véase la página Web: www.evolutinaere-zellen.org. 
17. En este sentido se evidencia la afinidad táctica de este proyecto con la practica activista y artística de colectivos y proyectos de arte contemporáneo como Parkfiktion en Hamburgo (www.parkfiktion.org) o Fiambrera Obrera en el marco español (www.sindominio.net/ fiambrera). Bajo esta perspectiva el espacio de dialogo y disenso, el trabajo directo como comunidades de práctica y la intervención directa se constituyen como materiales de trabajo en un campo expansivo del arte en relación a los movimientos sociales y el activismo (Felshin 1996), las políticas de trabajo colaborativo y nuevas pedagogías tal como recoje la web de Transductores (www.Transductores.net) o el proyecto de edicaión y wikipedia sobre prácticas colaborativas de Poliedrica (www-poliedrica.cat).

18. Miwon Known (2002) recompone una visión del site specific art o arte contextualizado lejos de comprender el espacio donde se asienta la obra de arte como un espacio neutro o consensual. Esta autora lo plantea como un espacio político de intervención o confrontación. Para ello toma como ejemplo la polémica intervención de Serra "Tilted Arc" de 1980, que se sitúa a través de los elementos materiales como una reacción estética opuesta al contorno social donde la obra se articula. Así Miwon Known expone un concepto problemático del arte en la comunidad ("art in community") a través de proceso de integración y participación donde el lugar específico se reconfigura como un filtro para el consenso y la neutralización de conflictos.

19. En este caso es necesario establecer una crítica profunda a aquellas habilidades enmarcadas en las programaciones educativas y curricula donde se fomenta una serie capacidades cognitivas en disminución de otro tipo de habilidades, menguando las capacidades culturales y sociales de un sector de alumnado determinado. Este tipo de estudios han derivado en la reconsideración del curriculum oculto (Torres 1991).

20. En este sentido estamos de acuerdo en afirmar el carácter pragmático critico de la educación artística tal como lo propone Imanol Aguirre (2000), donde se destaca la necesidad de una estética comprensiva, que no sólo se reduzca a un concepto de educación estética como recepción de objetos estéticos, sino también a la aplicación y transformación .

21. Actualmente Carmen Mörsch es doctora con un trabajo de tesis doctoral inscrita en la Universidad Carl von Ossietzky en Oldenburg bajo el título "Künstlerinnen machen Kunstvermittlung. Beschreibung eines Zwischenraums”.Véase ADK (2002:111). En esta tesis muestra comparativamente el papel de la educación y el espacio de legitimación de las prácticas de mediación artística en Alemania con las prácticas de educación y "community arts" de Inglaterra y el trabajo de centros de arte.

22. Eisner y Dobbs llevaron a cabo una investigación acerca del estatus de la educación artística en los departamentos educativos en los museos en Norteamérica. Dicha investigación dio lugar un informe de resultados titulado "The uncertain profession: Observations on the State of Museum Education in Twenty American Art Museums" (1986) donde se resaltaba la dificultad institucional y la falta de formación de dichos profesionales, pero al mismo tiempo se generaba una proyección paternalista y patriarcal que no detectaba otras posibilidades de agenda política y modos invisibles de resistencia de muchas educadoras o mediadoras de arte, casi condenando de antemano a este grupo mediante un estigma de profesión menor por ser un perfil incierto, cuanto dicha zona gris o intermedia puede ser al mismo tiempo una resistencia y estrategia política de crítica y cambio institucional. 